\title{
Rancang Bangun Sistem Informasi Kepegawaian dan Penilaian Kinerja Berbasis Web (Studi Kasus PT. XYZ)
}

\author{
Daniel Wahyu Suprayoga Prabowo ${ }^{1}$, Fardiana Karuniawati ${ }^{2}$ \\ ${ }^{1}$ Program Studi Manajemen Informatika, Universitas Merdeka Madiun, Jl. Serayu No.79, Madiun, 63133 \\ E-mail: daniel@unmer-madiun.ac.id \\ ${ }^{2}$ Program Studi Manajemen Informatika, Universitas Merdeka Madiun, Jl. Serayu No.79, Madiun, 63133 \\ E-mail: fardiana@unmer-madiun.ac.id
}

\begin{abstract}
As the rapid development of science, information and technology, humans are trying to find ways to help and facilitate the completion of their work quickly and efficiently. Due to the development of the information that requires an agency or company must be able to manage it, one of which is managing a large number of company employee data, of course it will be difficult if managing a large number of employee data manually. By using information systems, it is expected to facilitate the performance of agencies or companies in managing employee data at the company quickly and accurately.PT. XYZ is a garment production company that has many employees or employees, the employees consist of various educational backgrounds, and has a variety of years of service, every year rolling employees are held routinely for promotion, moving offices or moving work divisions in the production department. and others, the employee rolling criteria are based on evaluating employee performance within a certain period of time, even to dismiss employees is also seen from their performance appraisal. Referring to the problems above, it should be developed a staffing information system and webbased performance appraisal at PT. XYZ The system built can later be operated in various regions or places using the internet network, because PT. XYZ is not only in one place but there are in some places which are quite far from its headquarters, therefore the system that is built based on the web is considered suitable with the conditions in the field. From the employment information system and web-based performance appraisal at PT. XYZ, can be used as a tool to manage employee data, work attendance, monitoring, and evaluating employee performance.
\end{abstract}

Keywords—: Personnel Information System; Performance assessment; Personnel Staff.

\section{PENDAhuluaN}

Seiring pesatnya perkembangan ilmu, informasi dan teknologi, manusia berusaha menemukan cara untuk membantu dan mempermudah dalam menyelesaikan pekerjaannya dengan cepat dan efisien. Dikarenakan perkembangan informasi tersebut sehingga menuntut suatu instansi atau perusahaan harus bisa mengelolanya, salah satunya yaitu mengelola data pegawai perusahaan yang berjumlah banyak, tentunya akan kesulitan apabila mengelola data pegawai yang berjumlah banyak dengan cara manual. Dengan menggunakan sistem informasi diharapkan akan mempermudah kinerja instansi atau perusahaan dalam mengelola data pegawai pada perusahaan dengan cepat dan akurat.

Kinerja pada karyawan sangat penting dalam mencapai tujuan pada sebuah organisasi. Oleh karena itu diperlukan sebuah sistem penilaian yang dapat diandalkan untuk digunakan sebagai dasar penilaian kinerja dan pengembangan organisasi itu sendiri, prestasi karyawan diukur kinerjanya dengan tujuan agar setiap karyawan tahu sejauh mana kinerjanya untuk menghasilkan prestasi bagi organisasinya. Penilaian kinerja pada Pegawai Negeri Sipil, adalah penilaian secara berkala pelaksanaan pekerjaan seorang Pegawai Negeri Sipil. Penilaian kinerja yang disebut DP3 atau Daftar Penilaian Pelaksanaan Pekerjaan adalah daftar yang berisi hasil dari penilaian pegawai selama melaksanakan tugasnya dalam kurun waktu tertentu. DP3 juga digunakan sebagai acuan dan pertimbangan untuk kenaikan pangkat pegawai (Agustina dkk, 2013).

Sekarang ini pengolahan informasi bidang kepegawaian pada Bank Muamalat Indonesia sudah terkomputerisasi, yaitu datadata yang mengenai kepegawaian sudah berada di dalam suatu komputer. Namun sistem tersebut kurang optimal karena hanya sebagai database penyimpanan data pegawai yang bekerja di Bank Muamalat Indonesia, sedangkan untuk kegiatan-kegiatan administrasi kepegawaian lainnya seperti pengolahan data pensiun, data pendidikan, data pribadi pegawai, semua proses kegiatan masih dilakukan secara manual dan Bagian Kepegawaian harus membuka buku besar data kepegawaian untuk melihat data pegawai yang sudah memasuki umur pensiun. Dari penelitian ini menghasilkan sebuah rancang bangun sistem informasi kepegawaian Bank Muamalat Indonesia yang memudahkan proses administrasi kepegawaian yang sebelumnya manual menjadi terkomputerisasi (Hidayah, 2011).

Produktivitas sangat diutamakan sebagai ukuran keberhasilan pengoptimalisasian sumberdaya suatu organisasi atau instansi. Masalah yang dihadapi Dinas Koperasi Usaha Kecil dan Menengah Provinsi Sumatera Selatan yaitu proses administrasi dilakukan pencatatan di buku besar ataupun penyimpanan berkas dalam bentuk dosir maka membutuhkan begitu banyak buku dan mempersulit untuk menggali informasi karena data mengenai kepegawaian begitu banyak. Oleh sebab itu maka dibuatlah 
sistem infromasi manajemen kepegawaian (SIMPEG) dapat berperan penting untuk mempermudah dalam melakukan pendataan, pengajuan dan pelaporan agar mampu mengatasi masalah dengan baik (Retnowati,2017).

Sistem kepegawaian di SDN BINAKARYA 1 masih mengalami beberapa kendala, yakni seperti hal pengolahan data KGB, Kenaikan pangkat, kepensiunan serta penilaian pegawai. Dari masalah tersebut maka dikembangkanlah sistem informasi kepegawaian yang bertujuan untuk membantu proses pengajuan pensiun, KGB, kenaikan pangkat, penilaian pegawai sehingga dapat mempercepat pekerjaan. Hasil dari penelitian ini yaitu sebuah sistem informasi kepegawaian yang dapat membantu pegawai dalam menyiapkan persyaratan kenaikan pangkat kepensiunan penilaian pegawai dengan adanya sebuah database yang terintegrasi (Fachlevi dan Syafariani, 2017).

Di MAN 1 Padang Kepala TU masih kesulitan mengelola data karyawan karena tidak ada manajemen basis data yang dapat menyimpan, memproses, dan menjaga integritas data personalia. Untuk meningkatkan layanan di MAN 1 Padang sangat dibutuhkan Sistem Informasi Layanan Pegawai berbasis Web yang dapat mengelola layanan personalia, dari proses input data karyawan, proses cuti karyawan, proses mutasi karyawan dan proses pensiun karyawan saling terintegrasi secara keseluruhan. Sistem informasi kepegawaian ini menghasilkan aplikasi berbasis web yang dapat membantu Petugas Administrasi dalam meningkatkan efektivitas dan efisiensi dalam pelaksanaan kegiatan manajemen kepegawaian serta menampilkan informasi aktual dalam bentuk laporan data karyawan, informasi pensiun karyawan, riwayat mutasi karyawan dan riwayat cuti karyawan (Harisca dan Slamet, 2017).

PT. XYZ adalah Perusahaan produksi garment yang mempunyai banyak karyawan atau pegawai, para pegawai tersebut terdiri dari berbagai latar belakang pendidikan, dan mempunyai masa kerja bermacam-macam, setiap tahunnya secara rutin diadakan rolling pegawai untuk naik jabatan, pindah jabatan atau pindah divisi kerja di bagian produksi dan lain-lain, kriteria rolling pegawai tersebut berdasarkan penilaian kinerja pegawai dalam kurun waktu tertentu, bahkan untuk memberhentikan pegawai juga dilihat dari penilaian kinerjanya.

Merujuk dari permasalahan diatas sudah seharusnya dikembangkan sistem informasi kepegawaian dan penilaian kinerja berbasis web pada PT. XYZ. Sistem yang dibangun nantinya dapat dioperasikan di berbagai wilayah atau tempat dengan memakai jaringan internet, karena PT. XYZ tidak hanya di satu tempat saja tetapi ada di beberapa tempat yang jaraknya lumayan jauh dari kantor pusatnya, oleh karena itu sistem yang dibangun berbasis web dirasa cocok dengan kondisi di lapangan. Dari sistem informasi kepegawaian dan penilaian kinerja berbasis web di PT. XYZ tersebut, dapat digunakan sebagai alat untuk mengelola data pegawai, kehadiran kerja, monitoring, dan evaluai kinerja para pegawai.

\section{METODE PENELITIAN}

Metode penelitian yang dipakai dalam pengembangan sistem ini adalah waterfall model. Gambar 1. Waterfall model adalah suatu model proses untuk memodelkan suatu sistem perangkat lunak yang dibuat secara terstruktur dan berurutan dimulai dari definisi kebutuhan, desain sistem software, implementasi dan testing unit, integrasi dan testing sistem, operasi dan maintenance.

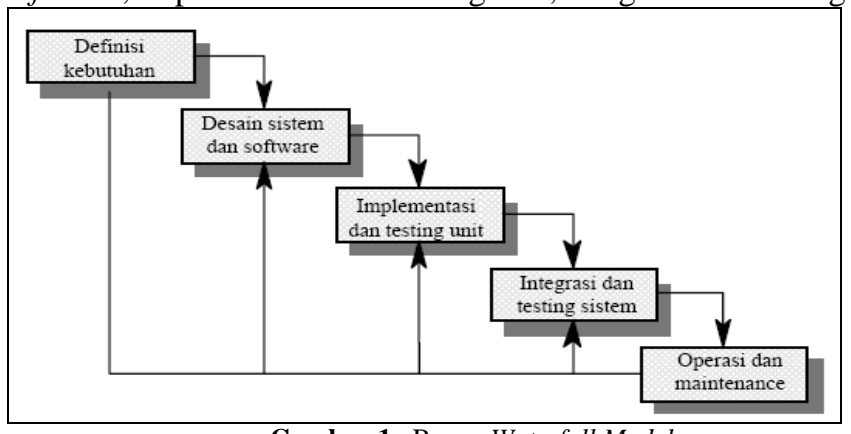

Gambar 1. Bagan Waterfall Model

Tahap-tahap yang dilakukan dalam waterfall model untuk membangun sistem menggunakan ASP.NET dan database Microsoft SQL Server 2008 dalam rancang bangun sistem informasi rekam medis berbasis web ini adalah:

\section{A. Definisi Kebutuhan}

Definisi kebutuhan dilakukan dengan melakukan penelitian pada PT. XYZ dengan cara Observasi yaitu mengamati langsung ke tempat penelitian dan mengambil data-data yang diperlukan. Tahap selanjutnya yaitu Interview atau tanya jawab dan diskusi kepada staff personalia perusahaan untuk mengetahui alur jenis pekerjaannya, selanjutnya apabila dikemudian hari ada data yang belum lengkap menghubungi melalui telepon dan email untuk memperoleh data kepegawaian, dengan begitu peneliti dapat melakukan analisa kebutuhan sistem yang dikembangkan berdasarkan data-data yang diperoleh. Selanjutnya Studi Pustaka dengan mempelajari jurnal penelitian sebelumnya dan artikel-artikel ilmiah yang berhubungan dengan sistem informasi kepegawaian.

B. Desain Sistem dan Software

Setelah proses penelitian selesai dan sudah didapatkan informasi yang lengkap, maka tahap selanjutnya adalah melakukan perancangan atau desain sistem yang akan dibuat sesuai dengan hasil penelitian, untuk mendapatkan gambaran sistem yang 
akan dikembangkan. Desain harus dapat mengimplementasikan kebutuhan yang telah disebutkan pada tahap sebelumnya. Jika pada tahap perancangan ini dilakukan evaluasi dan hasilnya masih belum memenuhi permintaan pengguna, maka akan dirancang kembali sampai permintaan pengguna benar-benar sesuai.

\section{A. Use Case Diagram}

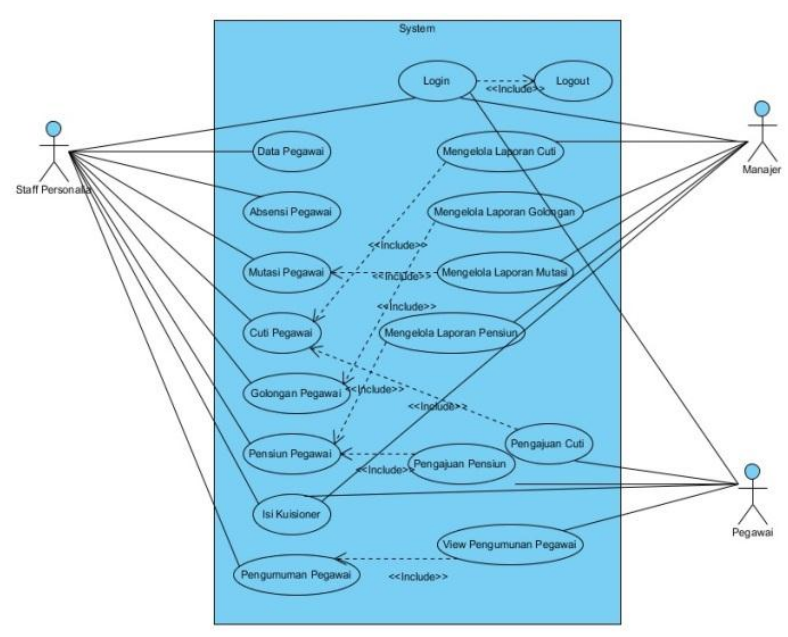

Gambar 2. Use Case Diagram

Gambar 2. Use Case Diagram menjelaskan bahwa didalam sistem terdapat 3 aktor yaitu Staff Personalia, Manajer, dan Pegawai, dari 3 aktor tersebut ketika masuk kedalam sistem harus login terlebih dahulu karena mempunyai hak akses dan tugas masing-masing.

\section{B. Sequence Diagram Pegawai}

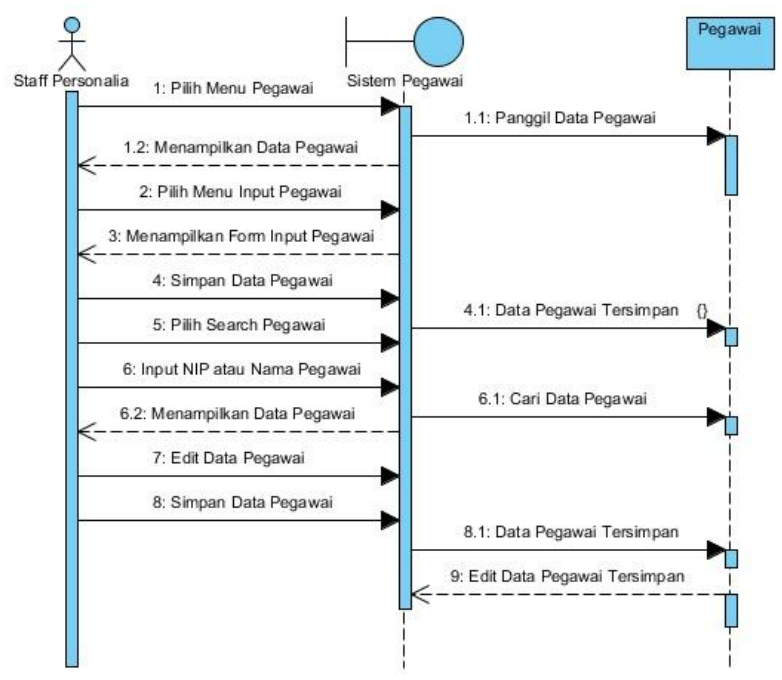

Gambar 3. Sequence Diagram Pegawai

Gambar 3. Sequence Diagram Pegawai menjelaskan bahwa Staff Personalia adalah sebagai aktor. Staff Personalia memilih menu pegawai, maka sistem akan menampilkan data pegawai dan aktor memilih button input pegawai untuk memasukkan data pegawai yang baru masuk atau diterima di perusahaan, selanjutnya sistem menampilkan Form Input Pegawai, disini Staff memasukkan semua data-data dari pegawai, setelah semua selesai di-input-kan maka klik button simpan di sistem dan sistem menyimpan data pegawai yang sudah di-input-kan oleh Staff Personalia. Kemudian di sistem terdapat fasilitas Search Pegawai untuk memudahkan pencarian data pegawai dengan cara memasukkan NIP atau nama pegawai, setelah NIP atau nama pegawai dimasukkan maka sistem menampilkan data pegawai, disini Staff Personalia bisa meng-edit, menambahkan dan menghapus, dari menu ini juga Staff Personalia dapat meng-input-kan mutasi pegawai, cuti pegawai, golongan pegawai, dan pensiun pegawai. Setelah data di edit, input, atau hapus maka Staff Personalia dapat mengklik button simpan, dan sistem akan menyimpannya. 


\section{Sequence Diagram Kuisioner}

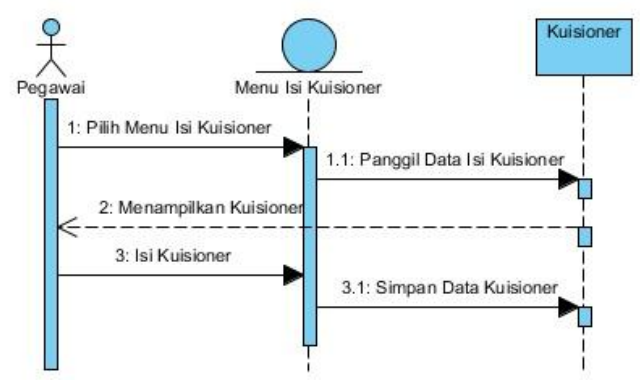

Gambar 4. Sequence Diagram Pegawai

Gambar 4. Sequence Diagram Pegawai menjelaskan bahwa Pegawai pada sistem memilih menu isi kuisioner, selanjutnya sistem akan menampilkan isi dari kuisioner, kemudian pegawai mengisi kuisioner tersebut dan klik tombol simpan maka sistem akan menyimpan kuisioner dari pegawai tersebut.

\section{Implementasi dan Testing Unit}

Tahap selanjutnya adalah melakukan implementasi dari rancangan sistem. Implementasi dibuat dengan menggunakan ASP.NET dan database Microsoft SQL Server 2008. Hasil perancangan langsung diuji untuk mengetahui kekurangan atau kesalahan pada sistem yang dibangun.

\section{Integrasi dan Testing Sistem}

Integrasi sistem diperlukan supaya sistem dapat berjalan seutuhnya dan untuk mengetahui apakah benar-benar memberikan manfaat dalam segi efisiensi dan efektifitas serta memudahkan pengguna dalam pemakaiannya. Pada tahapan ini sistem akan dievaluasi.

\section{Operasi dan Maintance}

Tahap terakhir adalah operasi dan maintance terhadap aplikasi sistem, serta terus mengevaluasi kelemahan-kelemahan yang ada untuk mendapatkan hasil yang maksimal. Pemeliharaan suatu aplikasi diperlukan, termasuk di dalamnya adalah pengembangan, karena aplikasi yang dibuat tidak selamanya hanya seperti itu.

Keuntungan menggunakan model ini yaitu mudah dan lebih efisien waktu pengerjaan, selain itu setiap tahapan akan dievaluasi secara teliti untuk mendapatkan hasil yang maksimal. Meskipun demikian, karena model ini melakukan pendekatan secara urut/sequential, maka ketika suatu tahap terhambat, tahap selanjutnya tidak dapat dikerjakan dengan baik dan itu menjadi salah satu kekurangan dari model ini.

\section{III.HASIL DAN PEMBAHASAN}

\section{A. Hasil Implementasi Sistem}

Setelah melakukan perancangan sistem informasi kepegawaian dan penilaian kinerja berbasis web, selanjutnya diimplementasikan langsung untuk mengetahui kekurangan atau kesalahan pada sistem yang dibangun. Tujuan dari pembuatan sistem ini adalah untuk membangun sebuah sistem informasi kepegawaian dan penilaian kinerja untuk membantu staff personalia dalam mengelola sistem administrasi kepegawaian yang di dokumentasikan didalam sebuah sistem informasi, disamping itu sistem ini juga digunakan sebagai alat bantu untuk penilaian kinerja dalam menilai pegawainya, penilaian kinerja digunakan untuk membantu kebijakan perusahaan menaikkan jabatan pegawainya, memutasi pegawainya, bahkan memberhentikan pegawainya. Berdasarkan proses pembangunan sistem informasi kepegawaian untuk penilaian kinerja berbasis web, hasil yang didapat sebagai berikut:

1. Sistem informasi kepegawaian dan penilaian kinerja berbasis web memproses dan mengelola data tiap-tiap pegawai PT. XYZ mulai dari pertama masuk kerja dan harian ketika pegawai tersebut bekerja.

2. Dalam sistem informasi kepegawaian dan penilaian kinerja berbasis web dapat di akses oleh para pegawai, staff kepegawaian, dan manajer mempunyai hak akses sendiri-sendiri karena mempunyai peran masing-masing, oleh sebab itu masing-masing mempunyai username dan password untuk login sistem.

3. Sistem informasi kepegawaian dan penilaian kinerja berbasis web dapat diakses dimana saja dengan jaringan internet, hal ini berguna apabila ada pengembangan perusahaan diberbagai tempat tidak perlu staff personalia pergi dari anak perusahaan ke perusahaan utama hanya untuk input data pegawai ke sistem.

4. Pada sistem informasi kepegawaian dan penilaian kinerja berbasis web dalam memproses dan mengolah data hanya dilakukan oleh staff personalia perusahaan saja, manajer hanya memvalidasi dari permintaan pegawai di sistem, seperti pegawai mengajukan cuti, mengajukan pengunduran diri dan pensiun. 
5. Sistem informasi kepegawaian dan penilaian kinerja berbasis web dapat membantu pimpinan perusahaan dalam mendapatkan laporan kinerja para pegawai pada setiap divisi, dengan begitu bisa menjadi pertimbangan apakah pegawai tersebut layak untuk naik jabatan, mutasi, atau harus diberi pelatihan dan pembinaan.

6. Sistem merekam semua history pegawai dalam kurun waktu tertentu, Pada PT. Xyz perusahaan melakukan penilaian kinerja pegawainya setiap tahun.

\section{B. Pembahasan}

Pada Gambar 5. Sistem Informasi Kepegawaian adalah tampilan sistem yang diakses oleh Staff Personalia, di form tersebut karyawan yang baru bekerja datanya dimasukkan, mulai dari nama, tempat tanggal lahir, jenis kelamin, status, agama, kewarganegaraan, foto, dan tanggal mulai bekerja. Selanjutnya pada bagian organisasi yaitu diisikan di bagian apa pegawai tersebut bekerja beserta jabatannya, pada bagian organisasi diisikan perusahaan tempat bekerja, area personal, sub personal, grup pegawai, jabatan dan level. Kemudian pada bagian bawah form terdapat alamat lengkap dari pegawai yang harus dimasukkan, terdiri dari alamat, kota, propinsi, kode pos, no. telepon, dan alamat email.

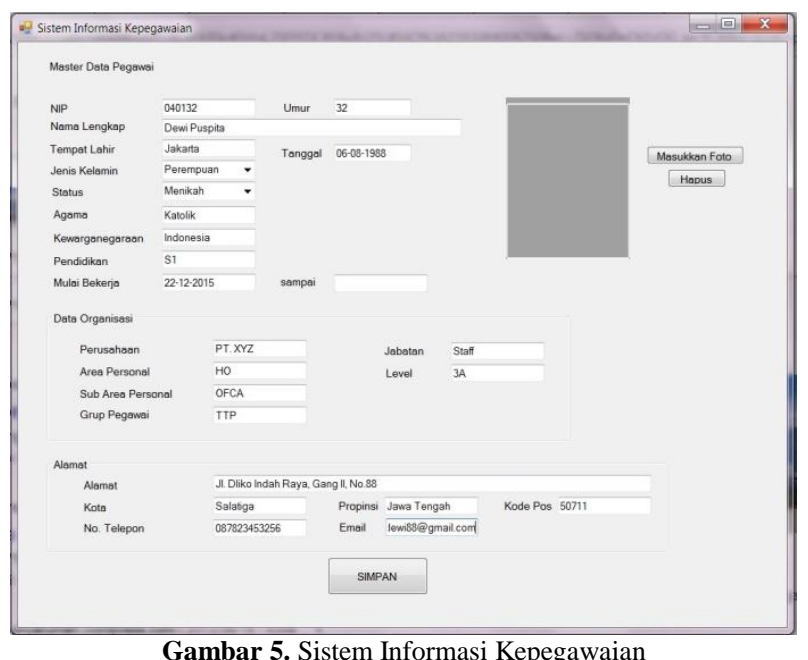

Pegawai juga mempunyai hak akses kedalam sistem meliputi pengajuan cuti, pengajuan pensiun, melihat pengumuman pegawai dan mengisi kuisioner. Pada Gambar 6. Pengajuan Cuti Pegawai yaitu jauh-jauh hari sebelum cuti pegawai harus mengajukan dan mengisi form cuti pegawai, karena harus divalidasi oleh manajer dahulu apakah pegawai tersebut diperbolehkan cuti atau tidak, selain itu untuk mempersiapkan penggantinya selama pegawai tersebut cuti apabila pegawai yang mengajukan cuti mempunyai jabatan yang penting dalam alur pekerjaan perusahaan. Form pengajuan cuti yang diisi meliputi NIP, Nama lengkap, tanggal mulai cuti, tanggal selesai cuti, alamat ketika sedang cuti, dan alasan keperluan cuti, setelah semuanya diisi klik tombol ajukan cuti, apabila ada kesalahan memasukkan data atau tidak jadi cuti maka klik batal pada sistem.

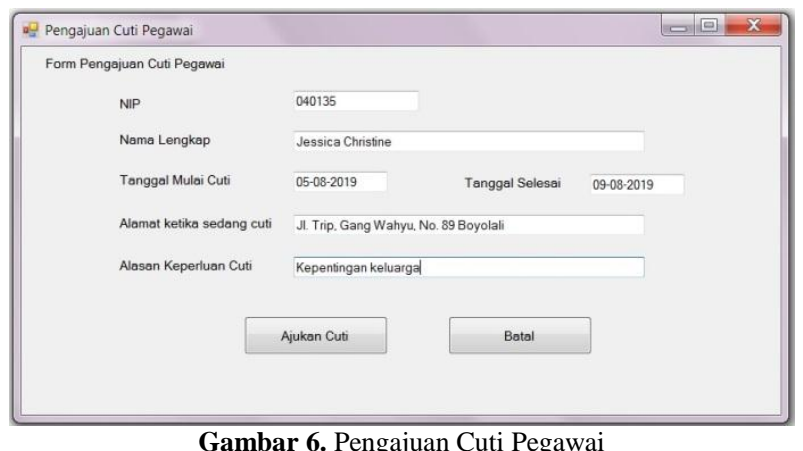

Pada Gambar 7. Kuisioner diisikan oleh semua pegawai perusahaan, kuisioner tersebut berguna untuk penilaian masingmasing pegawai dan juga masukkan untuk perusahaan, di form kuisioner pegawai menjawab pertanyaan dengan klik mana jawaban yang dianggap sesuai oleh pegawai yang mengisinya. 


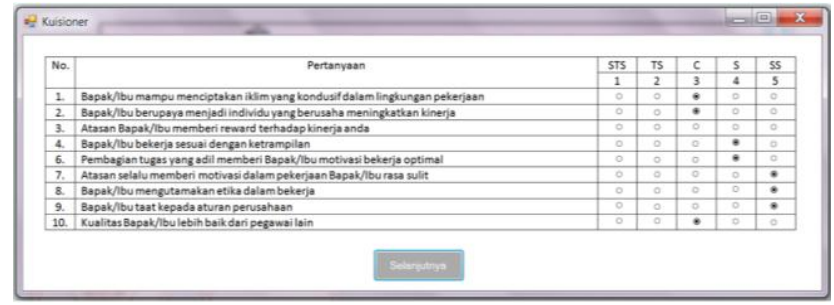

Gambar 7. Kuisioner

\section{IV.KESIMPULAN}

Berdasarkan hasil dan pembahasan sistem informasi kepegawaian dan penilaian kinerja berbasis web pada bab sebelumnya, dapat disimpulkan bahwa dengan mengimplementasikan sistem ini dapat membantu staff kepegawaian PT. XYZ dalam mengelola dan memproses data pegawai yaitu mempermudah proses pengajuan cuti, mutasi, kenaikan jabatan, pensiun, dan membantu penilaian kinerja pegawai. Sistem ini belum mempunyai sistem keamanan web yang memadai, untuk pengembangan penelitian selanjutnya bisa diterapkan web security agar data pegawai lebih aman

\section{DAFTAR PUSTAKA}

Agustina, D. M., Sunarto, M. D., \& Jatmiko, K. (2013). Sistem Informasi Penilaian Kinerja Pegawai pada Badan Kepegawaian dan Diklat Surabaya. Jurnal Sistem informasi dan Komputer Akuntansi, 2(2), 1-6.

Fachlevi, M. R., \& Syafariani, R. F. (2017). Perancangan Sistem Informasi Kepegawaian Berbasis Website Di Bagian Kepagawaian Sdn Binakarya I Kabupaten Garut. Simetris: Jurnal Teknik Mesin, Elektro dan Ilmu Komputer, 8(2), 553-558

Harisca, R., Huda, A., \& Slamet, L. (2017). Pengembangan Sistem Informasi Kepegawaian Berbasis Web Pada MAN 1 Padang. VoteTEKNIKA: Jurnal Vocational Teknik Elektronika dan Informatika, 5(2).

Hidayah, N. A. Rancang bangun sistem informasi kepegawaian studi kasus: Bank Muamalat Indonesia. repository.uinjkt.ac.id

Retnowati, D. (2017). SISTEM INFORMASI MANAJEMEN KEPEGAWAIAN (SIMPEG) PADA DINAS KOPERASI USAHA KECIL DAN MENENGAH PROVINSI SUMATERA SELATAN.[SKRIPSI] (Doctoral dissertation, UIN RADEN FATAH PALEMBANG) 